\title{
SPR Presidential Address: Micro- and Macro- Environments in Academic Pediatrics. Annual Meeting, Washington, D.C. 1982
}

\author{
JOSEPH B. WARSHAW* \\ Division of Perinatal Medicine, Departments of Pediatrics and Obstetrics and Gynecology, Yale University School of \\ Medicine, New Haven, Connecticut, USA \\ *Present address: Department of Pediatrics, University of Texas Health Science Center at Dallas, 5323 Harry Hines \\ Blvd., Dallas, Texas, USA
}

My talk today is about environments. My own area, perinatology and developmental biology, provides daily reminders of environmental effects on virtually every level of organization of human growth during critical developmental periods. It is apparent to any one involved with the care of newborns that much of the pathology encountered relates to perturbations of normal processes by adverse environmental influences.

Our usual academic and professional concerns relate to biologic, physiologic and behavioral maturation and its abnormalities, but we should also be vitally concerned about factors in our professional environment which can influence the personal growth and development experienced in our academic careers. It is this area about which I will speak today. Principles which have been established through the study of embryonic and fetal development, a micro-environmental system, can teach us much about growth and development in the macro-environment in which we spend our academic lives and to which we hope to attract our best students.

Let me very briefly share with you some examples of microenvironmental development which can be extended to this macroenvironment of academic pediatrics. From the very earliest stages of development, our surroundings are important. For example, as progressive cell division occurs in the fallopian tube, the embryo at the morula stage (Fig. 1) contains cells which occupy an external location and other cells which occupy an internal location totally surrounded by other cells. Cells which occupy the outside position form trophectoderm whereas those totally surrounded by other cells form the inner cell mass which becomes the embryo proper. The initial allocation of insideness or outsideness is random but these cells develop as a consequence of their position. Their surroundings give an initial developmental thrust and an irrevocable commitment in a certain direction.

Just a few weeks later, morphogenesis of the limb provides a superb example of how contact and communication can influence development (Fig. 2). The limb bud is comprised of a core of mesenchyme surrounded by an ectodermal jacket, the tip of which is a specialized tissue called the apical ectodermal ridge. The mesenchyme cells differentiate into structures of the limb in response to inductive interactions with the apical ectoderm. The mesenchyme in turn provides signals which help to maintain the ectodermal ridge. This interplay between ectodermal ridge and mesenchyme and the changes which occur at particular windows of development give the limb its characteristic phenotype.

Much of embryonic differentiation occurs through similar mechanisms involving cell-cell communication and signal transduction. Communication, interaction and informational exchange are important at every developmental stage.

For maturation and growth to be maintained there must be adequate provision of nutrients. Many of the problems that we see in perinatal medicine relate to late gestational impairment of uterine blood flow which can result in intrauterine growth retardation and its associated problems. Continued growth and development is totally dependent on the maintenance of nutritive support.

Let me come back to the general lessons that can be applied to academic environments (Table 1 ).

(1) Associations that we make early in our careers are just as critical to our fate as is the fate of cells situated in different areas of the morula.

(2) Contact and communication are just as vital to development in our macro-environment as they are in regulating morphogenesis of the limb. An academic pediatrician with promise will not thrive and develop unless development occurs in an environment in which there is contact, communication, and support by colleagues and teachers.

(3) Even when early embryonic and fetal development is normal, a late gestation fetus with a compromised supply of nutrients can become stunted. You don't have to be a perinatologist to recognize that nutrition and nurturing must be maintained. Individuals with the finest academic training will wither unless the proper environmental surroundings, communication, and contacts continue to be supportive.

(4) One of the major lessons that we learn from studying developmental systems at a micro level is that adverse influences can warp the process at every stage. Teratogens must be avoided. Just as certainly as thalidomide can result in a phocomelic limb or alcohol cause growth and mental retardation or rubella result in cataracts and deafness, adverse macro-environmental influences can blunt and retard academic careers. It is in this last area that I would now like to focus my remarks. Over the past several years, academic departments have faced a major threat to their academic environments.

This is our increasing dependence on monies derived from fee for service medicine to bolster medical school and departmental budgets. The unprecedented growth of medical school departments over the past 20 years and recent decreases in monies available from grants and university sources have resulted in a rush to raise clinical income. Our financial preoccupation has the potential to detract from our academic commitments to clinical scholarship, teaching, and research. Although these activities may prolong our academic lives, they do so at the expense of our academic health.

The changing pattern of financial support of medical schools during the past decade has resulted in this increased dependency on clinical income. In 1969, the Federal Government provided $52.6 \%$ of total medical school revenues compared with $29.1 \%$ in 1980. Professional fee income to medical schools increased from 65 million dollars a year in 1969 to 880 million dollars in 1980 


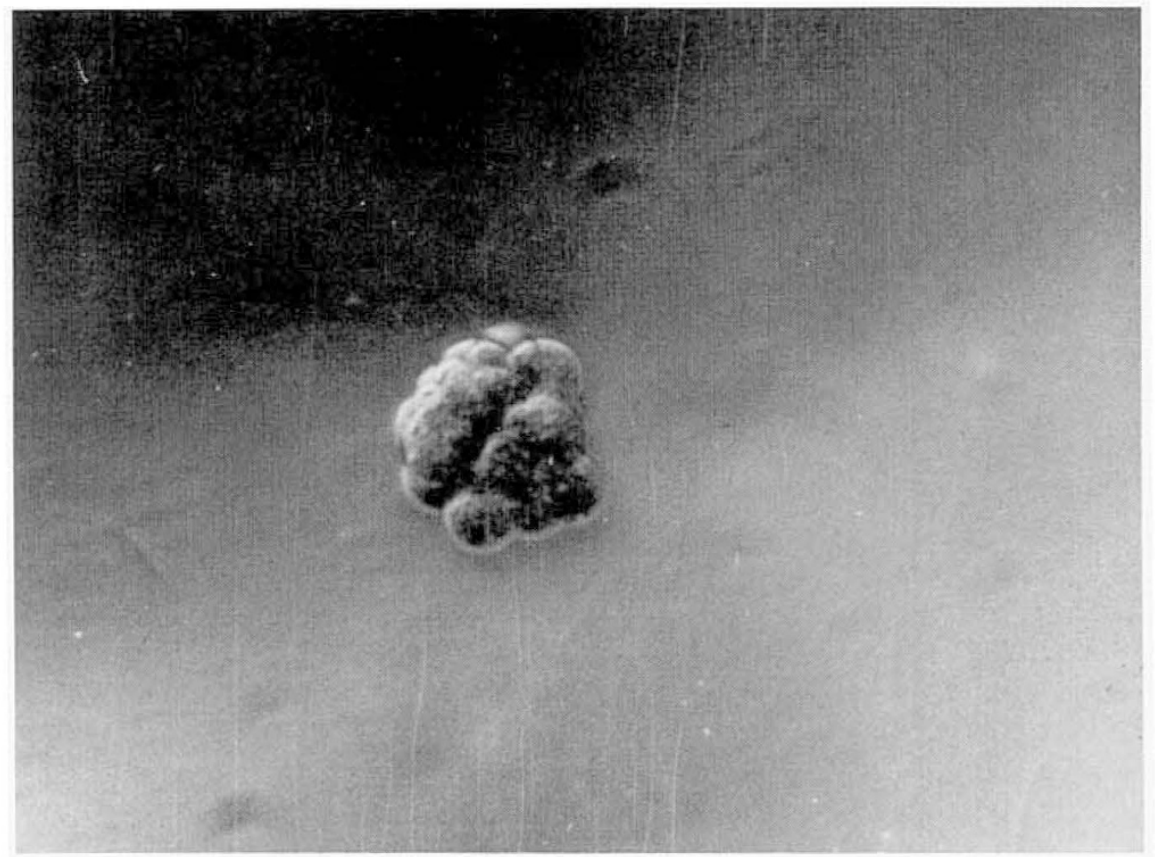

Fig. 1. Mouse Morula (Kindly provided by Professor Clement Markert, Department of Biology, Yale Univ., New Haven, Connecticut.

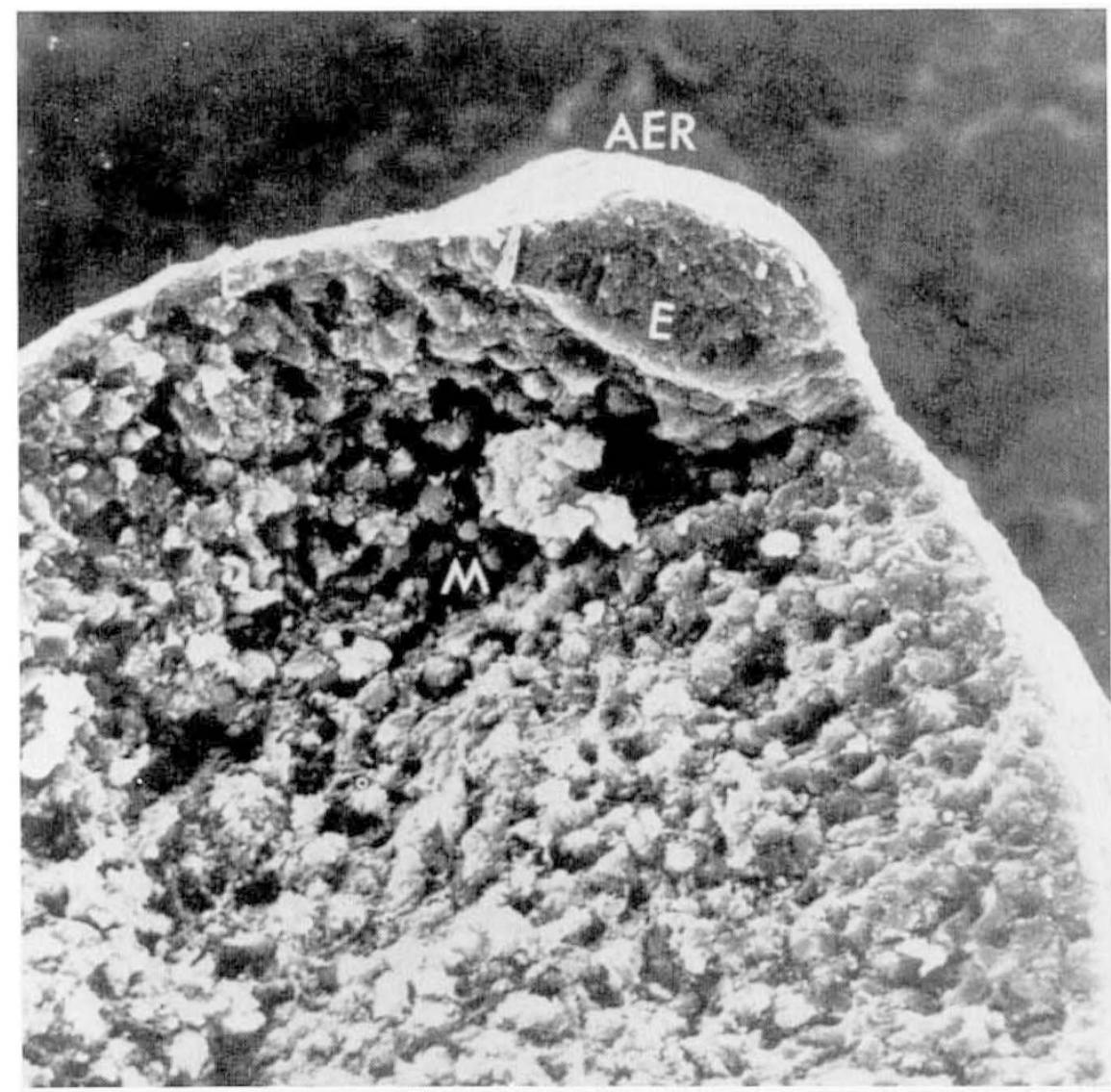

Fig. 2. Limb bud showing apical ectodermal ridge (AER) and mesenchyme (M) kindly provided by Dr. R.O. Kelly, University of New Mexico.

Table 1. Regulation of Development

Associations and Position

Contact and Communication

Nutrition and Nurturing

Avoidance of Adverse Influences and is probably well over a billion dollars a year by now. In 1979 , this was over $15 \%$ of all revenues of our schools as compared with less than $5 \%$ in 1968 . This is over $25 \%$ of our schools' unrestricted or operating budgets. These figures don't include service contracts to certain departments provided by hospitals and clinics. State appropriations to public medical schools have increased from 170 
million to over 1 billion dollars-but as a percentage of total revenues from only 12.4 to $18.9 \%$. For private schools these appropriations are less than $1.5 \%$ of the budget so that pressures to raise professional care income become even more compelling for these schools. In 1981, fewer than $50 \%$ of $\mathrm{NIH}$ renewal applications were funded creating even further budgetary pressures for our schools.

These factors all relate to the plight and decline of the clinical investigator who Wyngaarden calls an endangered species. There are proportionately fewer grants given to M.D. principal investigators as compared with $\mathrm{Ph}$.D's and there are proportionally fewer MD trainees seeking basic training. Not only are our faculties pressed by the expectations of schools and departments to raise clinical monies but an atmosphere of commercialism is created which sometimes shadows those concerns about scholarship and research which make academic medicine an attractive and enviable career.

Let me quote from a 1910 classic which was largely responsible for the privileged lives that we lead today, The Flexner Report.
Pediatrics is not even in the index of the report. At the time, it was discussed as a part of Internal Medicine. "The clinical professors will be on the common university basis: salaried, as other professors are. Of course, their salaries will be inadequate, i.e., less than they can earn outside,-all academic salaries paid to the right men are. But there is no inherent reason why a professor of medicine should not make something of the financial sacrifice that the professor of physics makes: both give up something-less and less, let us hope, as time goes on-in order to teach and to investigate. The clinical teacher should indeed not arbitrarily restrict his experience: he may wisely develop-preferably in close connection with the hospital-a consulting practice, assured thus that his time will not be sacrificed to trivial ailments. On the same basis, other university facilities are at the service of those who require unusually skillful aid; for at all points only good can come of educational contact with unsolved problems,-practical or other. But a consulting practice-developed in a professional or commercial, rather than in a scientific spirit-may prove quite as fatal to scientific interest as general practice."

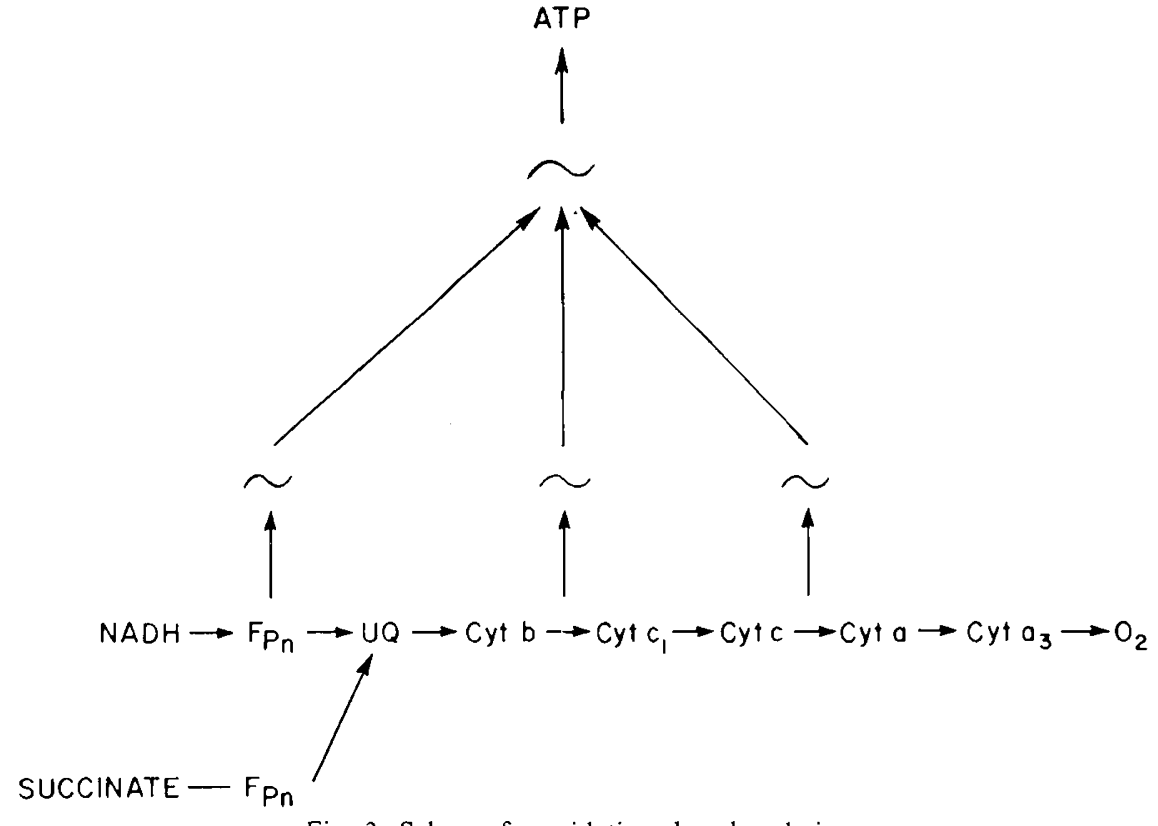

Fig. 3. Scheme for oxidative phosphorylation.

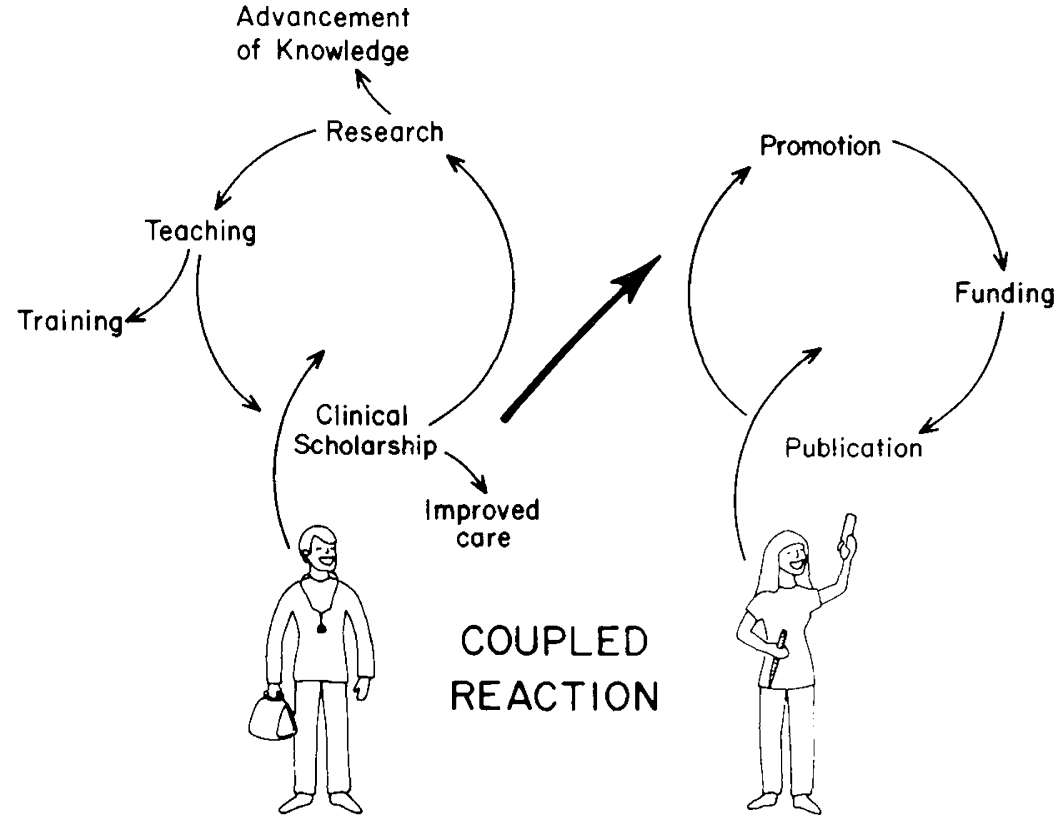

Fig. 4. The academic paradigm. 
There is also a lesson in the heuristic efficiency of metabolism. Figure 3 is a schematic representation of coupled oxidative phosphorylation, a very efficient energy producing mechanism, in which reducing equivalents generated from the citric acid cycle are oxidized by the mitochondrial electron transport chain to generate ATP, the energy carrier, which is used in all of metabolism. This is normally a conservative process with 3 moles of ATP being produced by every mole of NADH oxidized. Figure 4 shows a paradigm of academic pediatrics which is also presented as a coupled reaction in which clinical scholarship, research, and teaching in the cycle on the left are tightly coupled to promotion, and publication and funding to conduct research on the right. The byproducts of this reaction are new knowledge, the training of pediatricians, and improvements in the care of children. Activities are balanced.

Figure 5 suggests what clinical commercialism can do to academic activities. You may recognize some of your friends. Just as uncoupled oxidative phosphorylation utilizes extremely high levels of substrate but does not generate useful energy, uncoupled or futile clinical activities can drain the energy of the academic pediatrician. Increasing clinical practice for the purpose of generating clinical income saps our collective academic strength. Our goals have become more professional service income and better faculty practice plans in larger departments so that we can make more clinical dollars. As we labor under the burden of ever increasing requirements for patient care to raise dollars, our decreased academic productivity makes the availability of alternative sources of funding even more restricted. This situation is clearly a hazard to our developmental health.

The Venn diagram shown in Figure 6 is another way of looking at this. We strive for an environment in which research, teaching, and clinical activities are in appropriate balance. In the university and teaching hospital, there is a requirement for an appropriate amount of clinical service activity. We must maintain our clinical proficiencies. This is indicated by the area labeled "service" on the upper diagram. Our clinical activities are needed for our teaching and research and to contribute to the development of clinical scholarship and models of clinical excellence which can

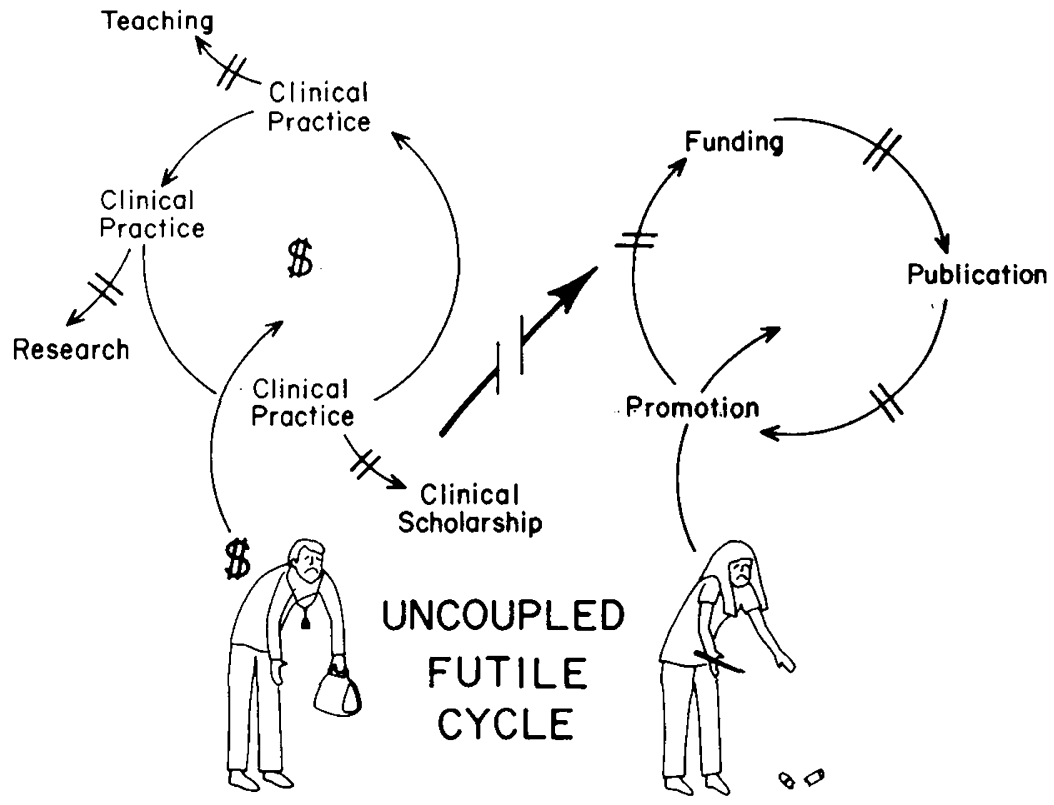

Fig. 5. Futile academic activities.

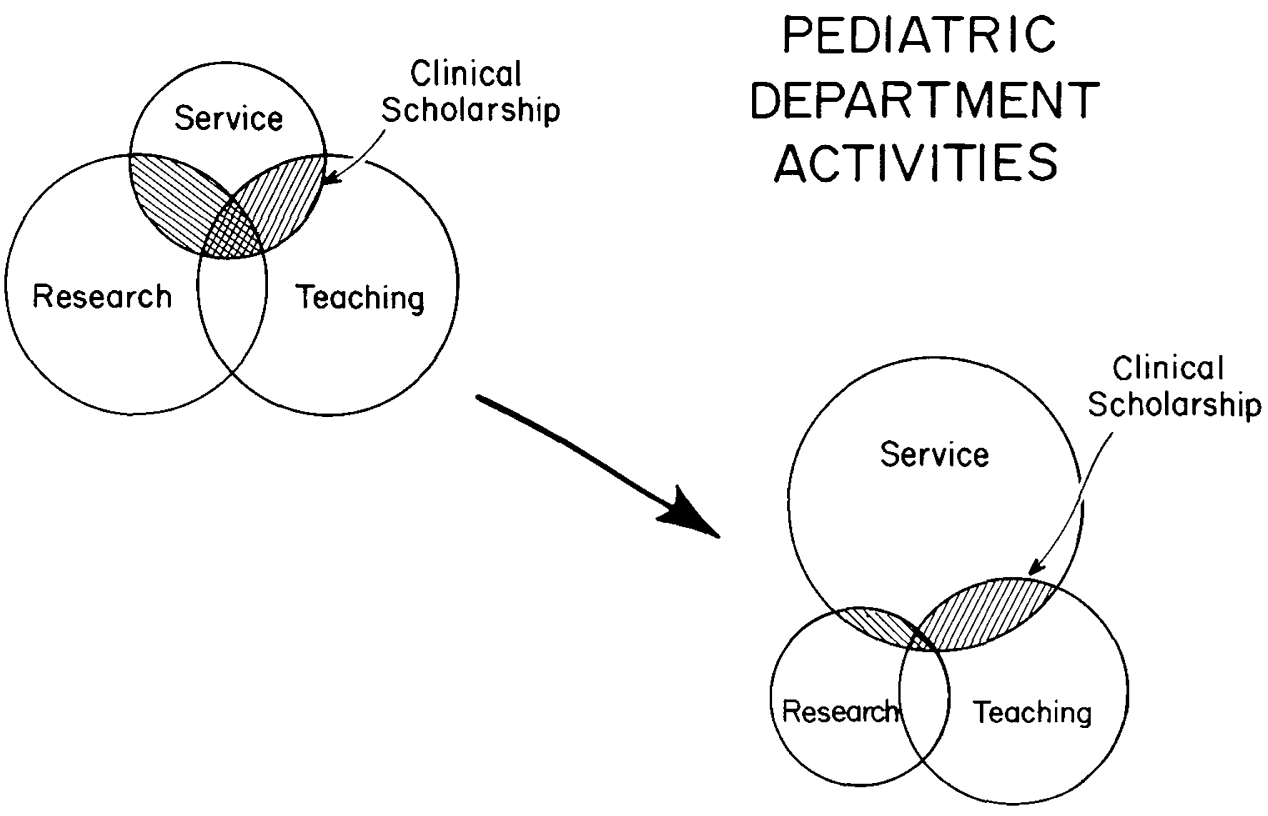

Fig. 6. Activities of academic departments. 
be transmitted to students and trainees. This is represented by the cross hatched area. Our increasing dependence on clinical dollars can warp these relationships. As shown in the lower portion of this figure, clinical service can become consuming, largely at the expense of research but also with an effect on our ability to transmit information to those in training and to our colleagues in the community. Research as well as clinical scholarship is diminished.

There are even more detrimental effects. Our trainees hear us complain about grants, about clinical overload, about committees, and about administrative responsibilities; however, most of us who are already established in our academic careers recognize what a marvelous and privileged life that we lead, the privilege of conducting research and asking a question to which we can provide the answer, the privilege of teaching, the privilege of feeling that we are contributing to the health of children. Although our salaries are not optimal they are adequate and we no longer require independent wealth to enjoy our academic careers as was largely the case in Flexner's day. We can enjoy the heady feeling that comes after the successful experiment or the acceptance of a manuscript, or having a grant funded and receiving the accolades of our peers. The recognition that we contribute to advancement of knowledge provides us with an enviable status. Our ability to influence students and trainees places us in a position of great responsibility. Through those that we train, we are the life line to the next generation of practicing pediatricians, a kind of academic genetic code. The standards of care and innovations in the practice of pediatrics that we establish will be the practice of the future. Distortions of this paradigm by increased service commitments and clinical activities can limit intrinsic potential of young investigators and restrict the contacts and associations, communication, and nurturing that are essential for academic growth in our macroenvironment.

How will our next generation of scholars and investigators be attracted to an academic system forced to become increasingly entrepeneurial, in which distinctions between practice and academics become blurred? How can we, the present generation, continue the superb traditions which attracted us to academic pediatrics? We are the reinvestment equity of our specialty, similar perhaps to the research and development group of a large industrial corporation. Without progress and the development of new products, a corporation may do well for a while but in the long term will wither. An industry such as AT\&T recognizes the need to sustain and support a Bell Laboratories.

I am not so naive to think that we can run departments of pediatrics in 1982 without clinical income. If I were, I would face the real world soon enough when I assume my own Chairmanship responsibilities next fall. We should certainly receive remuneration for services rendered in the course of the clinical care provided as we carry out our responsibilities to the community, and to the maintenance of scholarship and excellence. The stark realities created by bankrupt budgets propel us toward these alternatives. Dependency on fee for service dollars would not have arisen had departments not required such monies as a remedy for fiscal blight and starvation. But we must take care that the cure is not worse than the disease and maintain our balance and perspectives. Although we may be successful in improving earnings, the more successful we are, the more we may be isolated from our academic roots. We become diluted; we disrupt and threaten relationships with our colleagues in practice because of conflicts over billing and bed space. This is old hat in many institutions, fortunately less of a problem in pediatrics than in surgical areas. Nevertheless, in many instances, clinical service responsiblities of our faculties put us in direct conflict with the private community. Because of financial pressures, many schools are being driven to develop geographic full time practitioners who will generate the funds needed to support scholarly activities in the departments. This again is a short term solution which further blurs distinctions between academicians and practitioners.

Our departments are becoming free enterprise-market place units. If a market place exists it should be structured around scholarship and resources to conduct research not clinical income or faculty salaries as is sometimes the case, particularly in procedure oriented and intensive care specialties. We diminish what we can do best and should be doing primarily by making our departments free enterprise competitors with private practice. We create a hazardous environment for academic training. How can we get off the treadmill which is so well illustrated by the work of Escher? (Fig. 7).

What can we do to limit the effects of this macro-environmental teratogen? As in most complex issues, it is far easier to identify the problem than to develop clear solutions. My intent today is to primarily raise a red flag because I have no clear answers; however, there must be better alternatives than the intellectual bankruptcy that we face as a result of these major diversions from our primary goals.

Because child health is a public health issue that depends on pediatric training and research, the most logical avenue of support is the public; however, we have all witnessed how vulnerable we are to those who currently happen to be renting homes in Washington. We need a less capricious flow of public funds for our

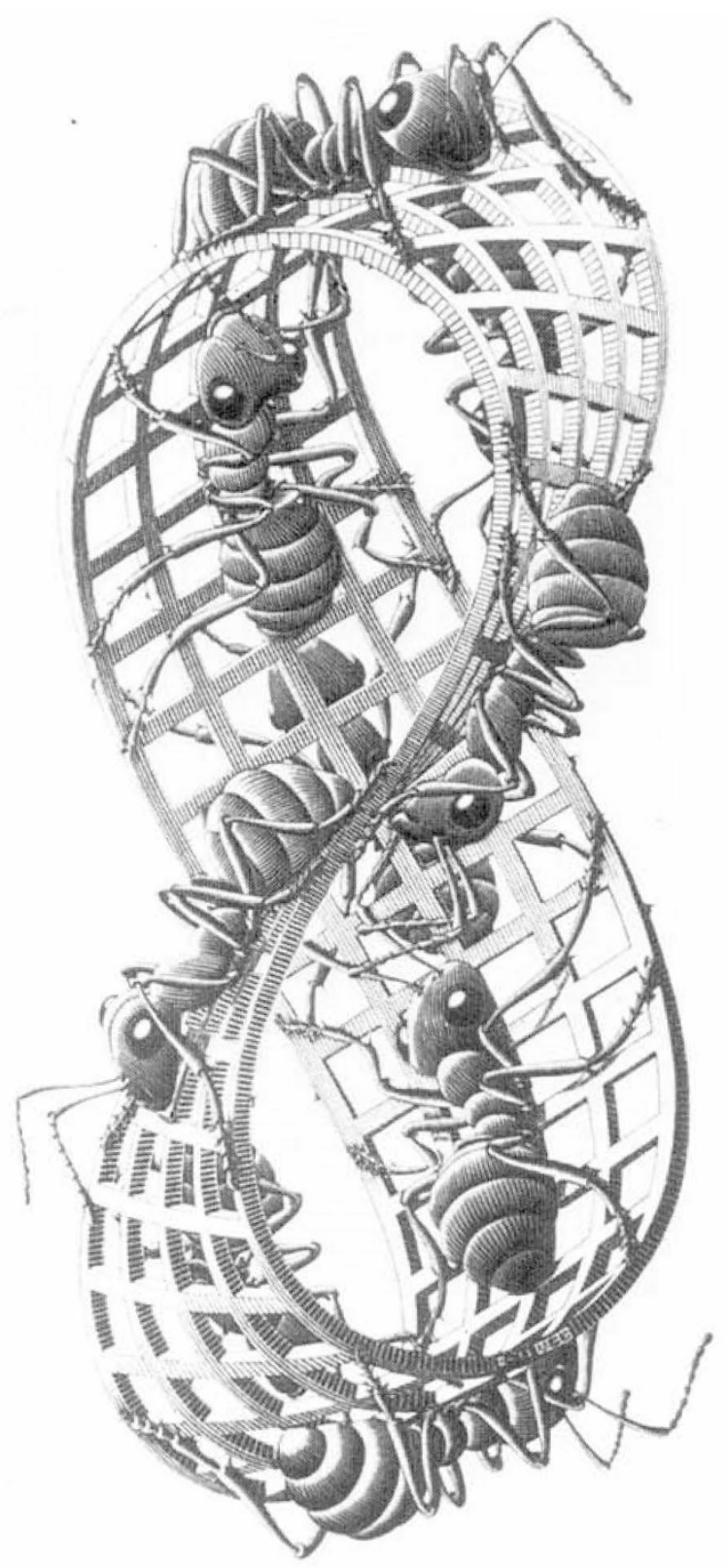

Fig. 7. Moebius strip 11, M.C. Escher. 
programs. A faucet turned on and turned off in response to new economic experiments does not encourage an environment attractive to those with the potential to improve the public's health. Our departments don't have knee jerk flexibility to adjust to year to year changes.

We must continue to make academic pediatrics an exciting option for our best students. How can we convince the talented trainee perhaps already $\$ 50,000$ in debt of the virtue of academic life where salaries, although improved, are still low. Elimination of guaranteed loan programs to medical students will make this problem even more critical. Medical student loans with generous paybacks should be available for those who stay in full time academic work. Perhaps groups such as the Academy or even industry can develop low cost loan programs in which payback arrangements would make it attractive to pursue academic careers. We should market and sell our specialty. Our departments and this Society has the responsibility to identify the best students and to convince them of the rewards of academic pediatrics.

Our universities must recognize that Departments of Pediatrics and other clinical departments require the same academic sustenance and support as the English Department or the Physics Department. They expect a clinical department to support itself with clinical monies but would be aghast if the chemistry department reduced its basic research to accept funds and commit students and faculty for the design of a better chewing gum. In both instances, academic goals are thwarted and the potential for scholarship diminished.

Our brethren in practice could do more to help. Is it enough for the practicing pediatrician to pay Academy of Pediatrics dues and subscribe to one or two pediatric journals and, ignore for the most part, the source and ongoing development of knowledge that is used in the day to day practice of pediatrics? I don't think so. Our medical schools and pediatric departments need more voluntary support from the private practicing community in both time and money. The private practicing community can wield political influence themselves, or through the families that they serve to influence political leaders to support programs and research of benefit to children.

Finally, our own departments face difficult choices. We should trim fat, perhaps even though it may be a bitter pill to swallow, shrink in size, if that will be the cost of maintaining excellence. As funds for research become more restrictive, we may have reached the point where not every medical school department of pediatrics can afford to have basic research carried by every subspecialty in the department. Departments should perhaps limit the areas in which fundamental research is carried out and focus on clinical scholarship in other areas which can set standards for clinical care, similar to departments in Europe. But every department should have some basic research to serve as a model for students and housestaff. We can enhance our research productivity by developing better bridges with basic science departments. Ph.Ds in clinical departments are playing an increasingly prominent role in departmental research activities and can help build these bridges. A true partnership of clinical and basic science investigators working as peers in clinical departments will likely be necessary to bring complex new technologies to bear on clinical problems; however, the clinical investigator must remain central to research activities in academic departments of pediatrics.

A definition of the word academic in Webster's unabridged dictionary is "very learned but inexperienced in the world of practical reality." We are learned but not wholly inexperienced in practical reality. My concern is that we are becoming too practical.

We must make certain that our macro-environment provides us with surroundings that will permit us to function as scholars. Our contacts and communications with colleagues should encourage new ideas. The important nurturing that is essential for continuing productivity requires that we work in a climate in which clinical scholarship, teaching, and the advancement of knowledge through research remain our overriding goal, not free enterprise financial activities. As developmental scientists, we are learning more and more about the micro-environment. We must pay much closer attention to our own macro-environmental health. 